\title{
Deskripsi Penggunaan Program Resitasi dalam Meningkatkan Kemampuan Membangun Free-Body Diagrams (FBDs)
}

\author{
Muhammad Reyza Arief Taqwa, Arif Hidayat, Sutopo \\ arief.reyza@yahoo.com \\ Pendidikan Fisika-Pascasarjana, Universitas Negeri Malang \\ Jl. Semarang 5, Malang
}

\begin{abstract}
Abstrak: Telah dikembangkan program resitasi yang berisi soal-soal latihan konseptual. Efektifitas penggunaannya telah dilihat pada 46 mahsiswa Universitas Negeri Malang, yang terdiri dari 24 mahasiswa S1 pendidikan Fisika dan 22 mahasiswa S1 Fisika. Hasil penelitian menunjukkan bahwa kemampuan mahasiswa dalam mengonstruksi FBDs meningkat setelah penggunaan program resitasi. Sebelum penggunaan program, hanya 4 orang mahasiswa $(8,70 \%)$ yang dapat menjawab soal dan setelah penggunaan program terdapat 43 orang mahasiswa $(93,48 \%)$ berhasil menjawab soal dengan benar.
\end{abstract}

Kata Kunci: Program resitasi, Free-Body Diagrams

\section{PENDAHULUAN}

Salah satu permasalahan yang umum terjadi yakni siswa datang ke kelas telah memiliki pengetahuan yang sering kali tidak sesuai dengan konsep ilmiah (Docktor \& Mestre, 2014; Hake, 1998; Halloun et al., 1985). Hal yang sedang banyak dilakukan oleh peneliti adalah merancang pembelajaran yang dapat memperbaiki kesalahan konsep yang sering dialami oleh siswa demi tercapainya perubahan konseptual. Agar perubahan konseptual pada siswa dapat tercapai, pembelajaran yang dirancang harus dapat memfasilitasi siswa untuk mengembangkan konsep baru dan memperbaiki cara berpikir sebelumnya (Docktor \& Metre, 2014; Atasoy, 2009; Arends, 2012; Frank, 2012).

Dinamika partikel merupakan salah satu materi dengan konten yang sering membuat siswa mengalami miskonsepsi. Selain memiliki cakupan luas, persoalan dinamika partikel memiliki tingkat kesukaran yang tinggi bagi siswa dan memiliki varian soal yang banyak, dapat dihadirkan pada beragam konteks dan representasi. Peneliti telah banyak mengungkap bahwa untuk menciptakan perubahan konseptual siswa maka dapat diberikan bantuan belajar berupa soal-soal konseptual dalam bentuk tugas tambahan, kuis, tutorial, simulasi, dan cara lainnya, yang dikemas dengan berbantuan program komputer baik online maupun offline (Demirci, 2003; Koenig et al., 2007; Henderson \& Harper, 2009; Morera et al., 2012; Yerushalmi et al., 2012; Sayre et al., Sornkhatha \& Srisawasdi, 2013; Olivera \& Olivera, 2013; Guo \& Shekoyan, 2014). Jika soal-soal latihan konseptual beserta balikannya diberikan dalam bentuk program komputer, maka dapat dirancang soal dengan jumlah soal yang banyak dengan konteks dan representasi yang beragam agar semakin baik dalam menguatkan konsep dan merubah konsepsi siswa (Jayanti et al., 2016; Sutopo et al, 2016; Afwa et al., 2016. Selain itu, dengan program komputer pemberikan balikan dan pembahasan soal dapat disajikan dalam bentuk gambar, visual, maupun audio visual agar dapat mempermudah dalam memberikan penekanan point penting yang harus diingat secara baik oleh siswa.

Secara umum dalam menyelesaikan persoalan terkait dinamika partikel, siswa harus mampu menggambarkan gaya yang bekerja pada benda dalam bentuk free-body diagrams (FBDs). Sebelum menggambarkan FBDs, siswa harus mengdentifikasian interaksi objek yang dikaji dengan objek yang mempengaruhinya terlebih dahulu yang dapat dibantu dengan membuat diagram interaksi (DI). Jika siswa mampu mengidentifikasi secara benar interaksi antar objek pada kasus yang disajikan dengan menggunakan DI, maka DI juga menjadi sarana untuk mengidentifikasi yang bekerja pada objek dan ini merupakan cara untuk membantu siswa dalam membangun free-body diagrams (Savinainen, 2013).

Untuk menyampaikan konsep gaya akan lebih baik jika menekankan gaya sebagai hasil interaksi (Reif, 1995; Brown, 1989; Hellingman, 1989; Jimenez \& Parales, 2001; Heuvelen, 1991). Hal tersebut merupakan salah satu cara memanfaatkan representasi visual untuk memvisualkan interaksi antar objek (Savinainen 
et al., 2013). Terdapat beberapa cara yang dapat digunakan dalam memvisualkan interaksi antar objek diantaranya adalah: skema sistem (Hestenes, 1997; Turner, 2003; Hinrichs, 2005), representasi simbolik dari interaksi (Jimenez \& Perales, 2001; Heuvelen, 1991; Hestenes, 1997; Turner, 2003; Hinrichs, 2005; Savinainen et al., 2005), diagram interaksi sistem (Tiberghien et al., 2009), dan diagram interaksi (Savinainen, dkk., 2013). Dari fakta yang telah ditemukan, penggunaan representasi visual seperti diagram interaksi dapat membantu perkembangan penguasaan konsep hukum ketiga Newton (Hinrichs, 2005; Savinainen et al., 2005; Nieminen et al., 2010).

Dalam menggambarkan FBDs terdapat beberapa kesulitan yang sering dialami siswa. Kesulitan umum yang siswa alami adalah menggambar gaya pada arah yang salah atau analisis vektor gaya gravitasi yang salah (Ayesh et al., 2010; Savinainen et al., 2013). Untuk membantu siswa membuat FBDs dengan benar, Savinainen et al., (2013) menyarankan digunakan interaction diagram (ID) sebagai bantuan. Dari fakta yang telah ditemukan, penggunaan representasi visual seperti diagram interaksi dapat membantu perkembangan penguasaan konsep hukum ketiga Newton (Hinrichs, 2005; Savinainen, dkk., 2005; Nieminen, et al., 2010). Oleh karena pentingnya FDBs dalam menyelesaikan persoalan terkait dinamika partikel dan Interaction Diagram (ID) maka dalam menyusun balikan pada bantuan belajar ini juga harus memperhatikan penggunaan FBDs atau pun ID dalam menuntun mahasiswa.

Pentingnya membangun FBDs dalam menyelesaikan soal dinamika partikel menuntut pengajar untuk dapat merancang pembelajaran yang mampu melatih siswa membangun FBDs. Tujuan dari artikel ini adalah untuk membahas perubahan kemampuan mahasiswa dalalm membangun FBDs setelah penggunaan program resitasi.

\section{METODE}

Penelitian ini dilakukan di Universitas Negeri Malang. Subjek penelitian terdiri atas 24 mahasiswa S1 pendidikan fisika dan 22 mahasiswa S1 fisika. Seluruh mahasiswa yang menjadi subjek penelitian sedang menjalani perkuliahan fisika dasar I.

Penelitian ini merupakan penelitian deskriptif kualitatif. Penelitian yang dilakukan bertujuan untuk merancang program resitasi yang berisi soal latihan konseptual beserta balikannya dan melihat efektifitas penggunnaan program dalam meningkatkan penguasaan konsep dinamika partikel. Untuk mengukur penguasaan konsep dinamika partikel digunakan 25 butir soal pilihar berganda. Pada artikel ini akan difokuskan untuk mendeskripsikan perubahan kemampuan mahasiswa dalam membangun Free-Body Diagrams (FBDs) setelah menggunakan program resitasi. Terdapat sebuah soal yang digunakan untuk melihat bagaimana kemampuan mahasiswa dalam membangun Free-Body Diagrams (FBDs).

Soal (pretest) diberikan setelah mahasiswa selesai membahas topik dinamika partikel. Setelah pretes mahasiswa mendapatkan program resitasi yang dikemas dalam program komputer offline agar mahasiswa dapat menggunakan program kapan saja. Dalam penelitian ini program komputer yang digunakan adalah Microsoft Office PowerPoint 2007. Pemilihan Microsoft Office PowerPoint 2007 dikarenakan program cenderung ringan dan mudah dioperasikan serta lebih banyak dikenal oleh mahasiswa secara umum. Pemberian program resitasi dilakukan selama 3 pekan, dengan 1 kali pertemuan dalam tiap pekannya. Pada pertemuan pertama mahasiswa diberikan 18 soal, begitupun untuk pertemuan kedua, sedangkan pertemuan ketiga mahasiswa diberikan 10 soal. Untuk setiap pertemuan mahasiswa diberikan waktu sekitar 100 menit untuk menjawab pertanyaan, membaca balikan, serta memahami pembahasan yang disajikan dalam bentuk video.

Soal yang digunakan dalam penelitian ini merupakan soal-soal yang dikembangkan dari FCI (Force Inventory Concept) maupun diadaptasi dari soal-soal buku fisika Universitas. Soal-soal yang digunakan dalam penelitian ini merupakan soal yang pernah digunakan dalam penelitian Sutopo et al., (2016) dan Jayanti et al., (2016). Gambar 1 ini menunjukkan soal pretes dan postes yang digunakan untuk melihat kemampuan mahasiswa dalam mengonstruksi FBDs. 
Balok A (bermassa $2 \mathrm{~m}$ ) dan B (bermassa $\mathbf{m}$ ) diletakkan di atas meja licin seperti gambar. Balok A didorong ke kanan dengan gaya konstan $P$ sehingga bergerak ke kanan. Selama gerakan tersebut, kedua balok selalu bersentuhan.

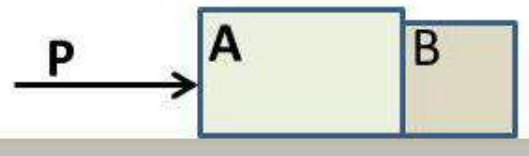

Diantara diagram-diagram gaya berikut, manakah yang paling tepat menggambarkan gaya-gaya yang bekerja pada balok B? Catatan: gaya dorong balok A ke B; gaya dorong balok B ke A.

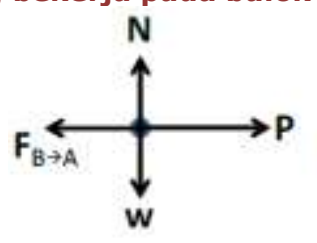

(A)

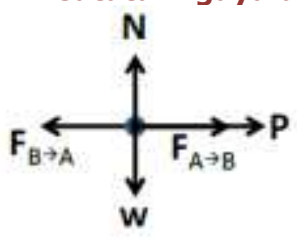

(B)

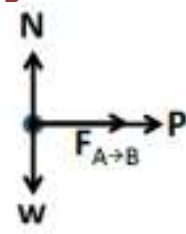

(C)

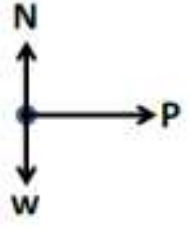

(D)

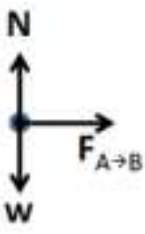

(E)

Gambar 1. Soal Yang Digunakan Untuk Melihat Kemampuan Mengkonstruksi FBDS

\section{HASIL DAN DISKUSI}

\section{Deskripsi Program dan Penggunaannya}

Jumlah soal yang disajikan dalam program resitasi adalah sebanyak 46 soal. Soal-soal dibuat dalam bentuk pilihan berganda dengan 3 hingga 6 opsi jawaban. Opsi-opsi jawaban disusun berdasarkan kemungkinan pemikiran mahasiswa dalam menjawab soal. Diharapkan seluruh opsi jawaban yang dihadirkan dapat mewakili seluruh pemikiran yang mungkin dimiliki oleh mahasiswa sehingga opsi jawaban untuk semua soal tidak sama.

Setiap mahasiswa yang memilih opsi salah akan mendapatkan balikan sesuai dengan kesalahan pemikiran yang mungkin terjadi. Kemudian mahasiswa diharuskan untuk mengerjakan ulang soal tersebut hingga benar. Jika mahasiswa memilih opsi benar, mahasiswa akan mendapatkan balikan berupa ucapan
Selamat, Anda telah berhasil menjawab soal ini dengan benar' lalu diberi link untuk melihat pembahasan yang disajikan dalam bentuk video. Gambar 2 menjelaskan alur penyajian soal beserta balikannya pada program resitasi.

Pemberian balikan dinilai penting dengan tujuan untuk menguatkan konsep mahasiswa ataupun memperbaiki pola pikir mahasiswa yang keliru (Taqwa \& Faizah, 2016). Butler \& Roediger (2008) juga berpendapat bahwa dampak pemberian balikan dapat memberikan efek positif dan mereduksi efek negatif. Soal latihan yang diberikan tanpa balikan justru dikhawatikan akan memperkuat miskonsepi yang terjadi pada siswa. Hal tersebut terjadi jika siswa memiliki konsepsi yang salah, dan opsi tersebut tersedia pada pilihan jawaban (Taqwa, et al., 2016). Oleh sebab itu, pemberian balikan dengan sesegera mungkin penting untuk dilakukan agar siswa tidak mengalami miskonsepsi karena latihan soal yang diberikan.

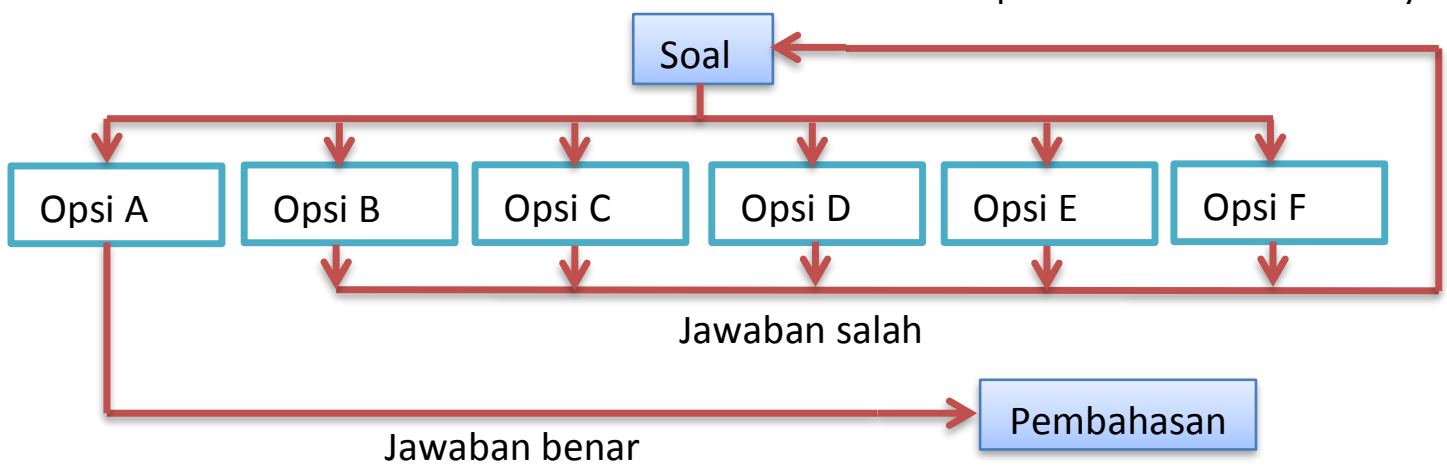

Gambar 2. Alur pemberian latihan soal penguatan konsep pada program resitasi (contoh opsi benar adalah A)

Deskripsi perubahan Kempuan Mahasiswa dalam Mengonstruksi FBDs
Hasil penelitian menunjukkan bahwa kemampuan mahasiswa dalam membangun 
p-ISSN 2338-3240, e-ISSN 2580-5924

FBDs menjadi lebih baik setelah penggunaan program resitasi. Hal ini dapat dilihat dari perubahan jumlah mahasiswa yang memilih opsi benar meningkat setelah mahasiswa menerima program resitasi. Perubahan jumlah mahasiswa yang memilih tiap opsi jawaban ditunjukkan oleh Gambar 3.

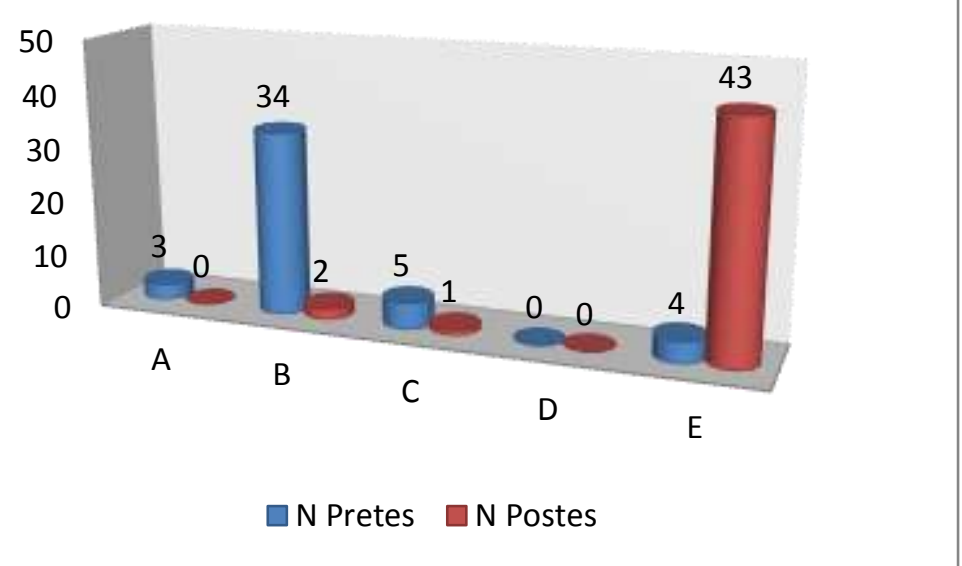

Gambar 3. Perubahan jumlah mahasiswa yang memilih tiap opsi jawaban (opsi jawaban benar adalah E)

Dari data tersebut terlihat bahwa sebelum pemberian program resitasi, mahasiswa yang mampu membangun FBDs hanya sebanyak 4 $(8,70 \%)$ mahasiswa. Temuan tersebut menunjukkan bahwa mahasiswa masih mengalami kesulitan dalam mengidentifikasi gaya dan menuangkannya dalam FBDs. Hal ini tentu menghawatirkan karena kemampuan dalam mengidentifikasi gaya merupakan kunci penting dalam memecahkan persoalan dinamika partikel (Sutopo, et al., 2016). Sebelum mengidentifikasi gaya, penting untuk menganalisis interaksi yang terjadi antara benda dan objek lain. Kemampuan ini perlu agar mahasiswa dapat membangun FBDs. Dan keseluruhan langkah tersebut penting untuk dikuasai oleh mahasiswa agar dapat memahami konsep dinamika partikel secara utuh.

Setelah pemberian program resitasi, terdapat $43(93,45 \%)$ mahasiswa yang memilih opsi $E$. Meskipun masih belum seluruh mahasiswa dapat menjawab dengan benar, namun hasil ini menunjukkan bahwa program resitasi dapat membantu pemahaman mahasiswa menjadi lebih baik. Data perubahan distribusi opsi jawaban yang dipilih dapat dilihat pada Tabel 1 .

TABEL 1. PRUBAHAN DISTRIBUSI OPSI JAWABAN YANG DIPPILIH MAHASISWA

\begin{tabular}{|c|l|r|r|r|r|r|r|}
\cline { 3 - 8 } \multicolumn{2}{c|}{} & \multicolumn{7}{c|}{ Pos } \\
\cline { 2 - 9 } \multicolumn{2}{c|}{} & A & \multicolumn{1}{l|}{ B } & C & \multicolumn{1}{l|}{ D } & E* & Jumlah \\
\hline \multirow{4}{*}{ Pre } & A & 0 & 0 & 0 & 0 & 3 & 3 \\
\cline { 2 - 8 } & B & 0 & 2 & 1 & 0 & 31 & 34 \\
\cline { 2 - 8 } & C & 0 & 0 & 0 & 0 & 5 & 5 \\
\cline { 2 - 8 } & D & 0 & 0 & 0 & 0 & 0 & 0 \\
\cline { 2 - 8 } & $E^{*}$ & 0 & 0 & 0 & 0 & 4 & 4 \\
\hline \multicolumn{2}{|c|}{ Jumlah } & 0 & 2 & 1 & 0 & 43 & 46 \\
\hline
\end{tabular}

Tabel 1 menunjukkan bahwa masih terdapat 3 mahasiswa yang tidak memilih opsi $\mathrm{E}$ pada saat pretes. $2(4,35 \%)$ mahasiswa tersebut memilih opsi B baik pada saat pretes maupun postes, sedangkan $1(2,17 \%)$ mahasiswa lainnya memilih opsi $B$ saat pretes namun saat postes memilih opsi $C$.

Mahasiswa yang memilih opsi B maupun $C$ berpikir bahwa pada benda $\mathrm{B}$ bekerja gaya $\vec{P}$. Mahasiswa tersebut masih tetap berpikir bahwa pada saat benda A mendapatkan gaya dorongan $\vec{P}$ maka gaya tersebut juga bekerja pada benda B. Hal tersebut menunjukkan bahwa mahasiswa masih belum 'memegang' konsep bahwa gaya selalu timbul akibat interaksi antara dua objek sehingga masih terjadi pemikiran yang keliru. Hal ini memperkuat hasil penelitian Savinainen et al., (2013), Heckler (2010), dan Rosengrant et al., (2005) yang menunjukkan bahwa siswa mengalami kesulitan dalam membangun FBDs dalam menyelesaikan soal dinamika partikel. Hal ini juga sejalan dengan hasil penelitian Jayanti et al., (2016) yang menemukan bahwa mahasiswa masih keliru dalam menggambarkan FBDs meskipun telah menggunakan program resitasi.

Namun demikian, secara umum penggunaan program resitasi untuk meningkatkan kemampuan mahasiswa dalam membangun FBDs dapat dikatakan berhasil. Dari hasi tes setelah penggunaan program menunjukkan bahwa terdapat $43(93,45 \%)$ mahasiswa yang memilih opsi E (kunci jawaban) pada saat postes. Dari 43 mahasiswa tersebut hanya 4 $(8,70 \%)$ mahasiswa yang memilih opsi $E$ pada saat pretes. Padahal saat sebelum pemberian program terdapat $3(6,52 \%)$ mahasiswa memilih opsi A, 31 (67,39\%) mahasiswa yang memilih opsi $B$, dan $5(10,87 \%)$ mahasiswa memilih opsi C.

Keberhasilan penggunaan program resitasi untuk meningkatkan kemampuan mahasiswa 
dalam membangun FBDs ini mungkin saja disebabkan oleh beberapa faktor, diantaranya:

(1) Jumlah soal yang diberikan relatif banyak, yakni 7 soal. Soal yang disajikan dalam program resitasi untuk meningkatkan kemampuan mahasiswa dalam membangun FBDs relatif lebih banyak dibandingkan soal untuk menguatkan konsep lainnya, sehingga memungkinkan mahasiswa sudah memahami dengan baik cara mengonstruksi FBDs karna jumlah soal yang disajikan. Soal yang diberikan juga disajikan dalam konteks yang beragram, hal ini bertujuan agar mahasiswa memiliki konsep yang lebih mendalam (Jayanti, et al., 2016).

(2) Pembiasaan pola pikir yang runut dalam membangunn FBDs. Seluruh soal yang dikhususkan untuk melatih kemampuan mahasiswa dalam membangun FBDs selalu dimulai dengan mengidentifikasi interaksi yang terjadi antara objek dengan objek lain. Setelah itu dilanjutkan dengan menggambarkan gaya apa yang timbul. Selain itu, seluruh soal yang bukan dikhususkan untuk melatih siswa dalam membangun diagram interaksi (misalkan untuk menentukan arah resulltan gaya, menentukan arah percepatan dan menentukan perbandingan besar gaya normal) juga dimulai dengan menentukan interaksi objek dan menggambarkan gaya yang timbul. Kesulitan siswa dalam menyelesaikan persoalan biasanya bukan disebabkan karena siswa tidak memiliki pengetahuan yang dibutuhkan untuk menyelesaikan soal, namun mahasiswa tidak dapat 'memanggil' kembali pengetahuan yang mereka miliki pada saat memecahkan persoalan (Hammer, 200). Hal ini terjadi karena konsep fisika yang dimiliki tidak terekam secara mendalam pada long term memory (Taqwa, et al., 2016; Afwa, et al., 2015).

(3) Terdapat soal yang mirip dengan soal. Soal latihan konseptual yang digunakan dalam melatih kemampuan mahasiswa dalam membangun FBDs memiliki satu buah soal yang mirip dengan soal tes. Perbedaannya, pada soal tes yang ditanyakan adalah FBDs pada benda $\mathrm{B}$ dan bidang dalam keadaan licin, sedangkan pada soal latihan konseptual yang ditanyakan adalah FBDs pada benda $\mathrm{A}$ dan bidang dalam keadaan kasar.

\section{KESIMPULAN DAN SARAN}

\section{A. Kesimpulan}

Program resitasi yang berisi soal-soal latihan konseptual berserta balikannya memiliki dampak memperbaiki pemahaman mahasiswa dalam membangun FBDs. Kemampuan mahasiswa dalam menbangun FBDs meningkat dari pretes ke postes. Pada saat pretes hanya 4 $(9,70 \%)$ mahasiswa yang mampu menjawab soal terkait FBDs dengan benar, sedangkan pada saat postes meningkat menjadi $43(93,48 \%)$ mahasiswa. Beberapa hal yang diduga menjadi faktor meningkatnya kemampuan mahasiswa dalam membangun FBDs adalah (1) soal latihan yang diberikan relatif banyak, (2) pembiasaan alur pikir yang runut dalam mengonstruksi FBDs, dan (3) terdapat satu soal latihan yang memiliki konteks mirip dengan soal tes.

B. Saran

Berdasarkan hasil temuan, dipandang perlu untuk membuat soal-soal konseptual yang disertai dengan balikannya dengan jumlah yang cukup. Soal-soal perlu disajikan dalam berbagai format representasi dan konteks agar dapat memperluas wawasan mahasiswa. Dalam menguatkan konsep sangat penting untuk membiasakan pola pikir mahasiswa yang benar.

\section{DAFTAR PUSTAKA}

Afwa, I. L., Sutopo, \& Latifah, E. 2016. Deep Learning Question untuk Meningkatkan Pemahaman Konsep Fisika. Jurnal Pendidikan: Teori, Penelitian, dan Pengembangan, 1(3): 434-447.

Afwa, I. L., Sutopo, \& Latifah, E. 2015. Perlunya program Deep Learning Question untuk meningkatkan penguasaan konsep kinematika mahasiswa fisika. Prosiding Seminar Nasional Fisika dan Pembelajarannya, Malang: Universitas Negeri Malang, 29 Agustus.

Arends, R.I. 2012. Learning to Teach: 9th edition. New York: McGraw-Hill.

Atasoy, B. 2009. The Effect of a Conceptual Change Approach on Understanding of Sudennts' Chemical Equilibrium Concept. Journal Research and Science \& Technologycal Education. 27: 267-282.

Ayesh, A., Qamhieh, N., Tit, N., \& Abdelfattah, F. 2010.The effect of student use of the free-body diagram representation on their performance. Educational Research, 1(10): 505.

Brown, D. E. 1989. Students' concept of force: the importance of understanding Newton's third law. Phys. Educ., 24: 353-358.

Butler, A.C., \& Roediger, H.L. 2008. Feedback enhances the positive effects and reduces the negative effects of multiple-choice testing. Journal of Science Education and Technology. 36(3): 604-616. 
Demirci, N. 2003. Dealing with misconceptions about force and motion concepts in physics: a study of using web-based physics program. Hacettepe Universitesi Egitim Fakultesi Dergisi, 40-47.

Docktor, J. L. \& Mestre, J. P. 2014. Synthesis of disciplinebased education research in physics. Physical Review Special Topic Physics Education Research, 10, 020119, 1-58.

Frank, W. 2012. Interactional Processes for Stabilizing Conceptual Coherences in Physics. Physical Review Special Topic - Physics Education Research., 8, 020101.

Guo, W., \& Shekoyan, V. 2014. Facilitation of studentcentered formative assessment using reflective quiz self-corrections in a calculus physics course. 121st ASEE Annaul Conference \& Exposition. 8450, 1-15.

Hake, R. R. 1998. Interactive-engagement versus traditional methods: A sixthousand student survey of mechanics test data for introductory physics. American Journal of Physics, 66(1): 64-74.

Halloun, I. A., Hestenes, D. 1985. The initial knowledge state of college physics students. American Journal of Physics, 53(11): 1043-1055.

Hammer, D. 2000. Students resource for learning introductory physics. American Journal of Physics, Physics Education Research Supplement, 68 (S1): S52-S59.

Heckler, A. F. 2010. Some consequences of prompting novice physics students to constrct force diagrams. International Journal of Science Education, 32(14): 1829-1851.

Hellingman, C. 1992. Newton's third law revisited. Phys. Educ., 27: 112-115.

Henderson, C. \& Harper, K., A. 2009. Quiz corrections: Improving learning by encouraging students to reflect on their mistakes. The Phisics Teacher, 47: 581-586.

Hestenes, D. 1997. Modeling Methodology for Physics Teachers. AIP Conf. Proc., 399: 935

Heuvelen, A. V. 1991. Overview, case study physics. American Journal of Physics, 50(1): 898-907.

Hinrichs, B. 2005. Using the system schema representational tool to promote student understanding of Newton's third law. AIP Conf. Proc. 790, 117-120.

Jayanti, I.B.R., Wartono, \& Sutopo. 2016. Dampak program resitasi terhadap perubahan konseptual mahasiswa pada topik hukum III Newton, Jurnal Pendidikan: Teori, Pendidikan, dan Pengembangan, 1(2): 256264.

Jimenez, J. D., \& Perales, F. J. 2001. Graphic representation of force in secondary education: analysis and alternative educational proposals. Phys. Educ., 36: 227-235.

Koenig, K. M., Endorf, R. J., \& Braun, G. A. 2007.Effectiveness of different tutorial recitation teaching methods and its implications for ta training.Physical Review Special Topics Physics
Morera, L. S., Azofra, A. A., \& Hernandez, L. G. 2012 Analysis of online quizzes as a teaching and assessment tool. Journal of Technology and Science Education, 2 (1): 39-45.

Nieminen, P., Savinainen, A. dan Viiri, J. 2010. Force Concept Inventory-based multiple-choice test for investigating students' representational consistency. Physical Review Special TopicsPhysics Education Research, 6, 020109.

Oliveira, P. C. \& Oliveira, C. G. 2013. Using conceptual questions to promote motivation and learning in physics lectures. European Journal of Engineering Education, 38 (4): 417-424.

Reif, F., Allen, S. 1992. Cognition for Interpreting Scientific Concepts: A Study of Acceleration. Cognition and Instruction, 9(1): 1-44.

Rosengrant, D., Heuvelen, A. V., \& Etkina, E. 2005. Case Study: Students' use of Multiple Representations in Problem Solving. Proceeding of The 2005 PERC: AIP Conference Proceedings.

Savinainen, A., Makynen, A., Nieminen, P., \& Viiri, J. 2013 Does using a visual-representation tool foster students' ability to identify forces and construct free-body diagrams?. Physical Review Special Topic - Physics Education Research, 9, 010104.

Savinainen, A., Scott, P., \& Virri, J. 2005. Using a Bridging Representation and Social Interactions to Foster Conceptual Change: Designing and Evaluating an Instructional, Sequence for Newton's Third Law. Sci. Educ., 89: 175-195.

Sayre, E. C., Franklin, S. V., Dymek, S., Clark, J. \& Sun, Y. 2012. Learning, retention, and forgetting of Newton's third law throughout university physics.Physical Review Special Topics Physics Education Research, 8, 010116.

Sornkhatha, P. \& Srisawasdi, N. 2013. Supporting conceptual development in newton's laws of motion using an interactive computer-simulated laboratory environment. Procedia Social and Behavioral Sciences, 2010-2014.

Sutopo, Ida, B.R., \& Wartono. 2016. Efektivitas program resitasi berbasis komputer untuk meningkatkan penguasaan konsep mahasiswa tentang gaya dan gerak. Jurnal Inovasi dan Pembelajaran Fisika, 3(1): 1-9.

Taqwa, M. R. A., Hidayat, A., \& Sutopo. 2016. Recitation program based on multi representation needed to increasing the kinematics conceptual understanding. Paper on International Seminar on Science Education (ISSE), Yogyakarta: Graduate School, Yogyakarta University, 29 October.

Taqwa, M. R. A., \& Faizah, R. 2016. Perlunya Program Resitasi dalam Meningkatkan Penguasaan Konsep Dinamika Partikel Mahasiswa. Makalah pada Seminar Nasional Pembelajaran IPA Ke-1, Malang: Universitas Negeri Malang, 1-2 Okrober.

Tiberghien, A., Vince, J., \& Gaidioz. P. 2009. Design-based research: Case of a teaching sequence on mechanics. Int. J. Sci. Educ. 31(17), 2275-2314. 
Turner, L. 2003. System schemas. Phys. Teach. 41: 404408.

Yerushalmi, E., Cohen, E., Mason, A., \& Singh, C. 2012. What do students do when asked to diagnose their mistakes? Does it help them? I. An typical quiz context. Physical Review Special Topics Physics Education Research, 8, 020109. 